\title{
Pelatihan Upaya Kesehatan Kerja Bagi Masyarakat Cipayung Kota Depok
}

\author{
Azizah M. Fitri ${ }^{1}$, Fajaria Nurcandra ${ }^{2}$, Terry Y.R. Pristya ${ }^{3}$ \\ 1,2,3 Program Studi Kesehatan Masyarakat, Universitas Pembangunan Nasional “Veteran” Jakarta \\ email: azizahmusliha@upnvj.ac.id
}

\begin{abstract}
An initial survey that had been done found that the location of the settlement where residents of cipayung lived was very close to the location of the Cipayung Landfill. The unhealthy environment tended to cause disease and any other health problems, so that efforts needed to be made to overcome this, one effort that could be done is training on health. This counseling activity was attended by 21 residents living in the village of West Bulak which is the closest residential location to the Cipayung landfill site. Wilcoxon test results on the pre-test and post-test scores of participants showed a P-value of 0.001 which means that there were differences in the level of knowledge of the participants after attending counseling. The average value of pretest and post-test had a difference of 34.5 shows that counseling that has been carried out is able to increase knowledge.
\end{abstract}

Keywords: Occupational Health Effort, Landfill

\begin{abstract}
Abstrak
Survei awal yang dilakukan menemukan bahwa lokasi pemukiman warga cipayung sangat berdekatan dengan lokasi Tempat Pemrosesan Akhir (TPA) sampah cipayung. Lingkungan yang tidak sehat di sekitar lokasi TPA dapat mengakibatkan gangguan kesehatan pada masyarakat sehingga perlu dilakukan upaya untuk mengatasi hal tersebut, salah satu upaya yang dapat dilakukan adalah pelatihan mengenai kesehatan. Kegiatan penyuluhan ini diikuti oleh 21 warga yang tinggal di kampung bulak barat yang merupakan lokasi pemukiman terdekat dengan lokasi TPA Cipayung. Hasil uji wilcoxon terhadap nilai pre-test dan post-test peserta menunjukkan nilai $P$ 0,001 yang berarti bahwa terdapat perbedaan tingkat pengetahuan setelah mengikuti penyuluhan. Selisih sebesar 34,5 pada nilai rata-rata pre-test dan post-test menunjukkan bahwa penyuluhan yang telah dilaksanakan mampu meningkatkan pengetahuan warga di sekitar TPA Cipayung.
\end{abstract}

Kata Kunci: Upaya Kesehatan Kerja, Tempat Pemrosesan Akhir

\section{PENDAHULUAN}

Tempat Pemrosesan Akhir (TPA) Cipayung merupakan tempat penampungan sampah terbesar di Kota Depok yang terletak di Kelurahan Cipayung, Kecamatan Cipayung. TPA Cipayung menampung dan memproses sebagian besar sampah dan limbah yang dihasilkan oleh masyarakat di Kota Depok. Sebanyak 550 ton sampah diperkirakan dikirim setiap hari dan ditampung di TPA Cipayung untuk diproses (Pemerintah Kota Depok, 2019).

Pekerjaan pengepul dan pengangkut sampah merupakan salah satu pekerjaan dengan tingkat risiko dan bahaya tinggi (Tibbetts, 2013). Banyak warga baik yang bekerja sebagai pengepul dan pengangkut sampah di area TPA Cipayung, maupun warga yang sehari-hari beraktivitas dekat area TPA Cipayung bekerja dan tinggal di sekitar lokasi TPA dimana banyak sumber bahaya berada. Bahaya yang dihadapi oleh para pekerja di sekitar TPA Cipayung dapat berupa bahaya biologis yang bersumber dari sampah dan limbah, bahaya ergonomi yang bersumber dari kegiatan manual handling, serta bahaya fisik yang berasal dari lingkungan kerja.

Bahaya biologis yang dihadapi warga yang beraktivitas dan bekerja di TPA Cipayung bersumber dari sampah yang merupakan sumber penyakit, baik secara langsung maupun tak langsung(Budiono, Jusuf and Pusparini, 2016). Secara tidak langsung, sampah juga merupakan 
sarang vektor-vektor penyakit yang berbahaya. Berbagai penyakit yang dapat muncul karena sampah antara lain adalah penyakit kulit (dermatitis), diare, cacingan, demam berdarah, serta penyakit saluran pernafasan (Fithri, 2017). Penyakit-penyakit ini merupakan ancaman bagi pekerja yang bersinggungan langsung dengan sampah.

Selain bahaya biologis akibat sampah, para warga yang bekerja dan beraktivitas di sekitar TPA Cipayung juga berhadapan dengan bahaya kimia, fisik, dan ergonomi. Bahaya kimia berasal dari substansi kimia yang mungkin terkandung dalam limbah atau hasil dari pembusukan limbah seperti gas CH4, gas H2S, dan debu (Sukrorini et al., 2014). Bahaya fisik dapat berasal dari lingkungan sekitar TPA yang panas, sedangkan bahaya ergonomi dapat bersumber dari aktivitas manual handling yang dilakukan oleh para pekerja.

Bahaya dan risiko yang dihadapi tersebut harus dikendalikan sehingga tidak menimbulkan kerugian bagi pekerja (Kurniawidjaja, 2010). Upaya pengendalian bahaya dan risiko harus dilaksanakan dengan tersistematis dan sebaik-baiknya untuk mencegah timbulnya kecelakaan kerja maupun penyakit akibat kerja, namun di lokasi dimana warga sekitar TPA Cipayung berada belum ada upaya yang berarti dalam pengendalian bahaya dan risiko akibat kerja.

\section{METODE}

Upaya Kesehatan Kerja TPA Cipayung adalah bentuk Upaya Kesehatan yang melibatkan masyarakat yang yang bekerja dan beraktivitas di sekitar lokasi TPA Cipayung. Kegiatan UKK ini akan melibatkan masyarakat sekitar TPA Cipayung melalui kepesertaan pada kegiatan penyuluhan dan pelatihan kader kesehatan mengenai pentingnya penerapan upaya kesehatan kerja. Keterlibatan kader kesehatan terutama sangat diperlukan demi mendukung penyelenggaraan kergiaatan ini. Pentingnya keterlibatan kader kesehatan karena masyarakat cipayung mengganggap bahwa kader kesehatan adalah tokoh penting yang menyebarluaskan informasi kesehatan. Peran tokoh masyarakat seperti kader kesehatan sangat penting karena kelompok ini adalah kelompok yang memiliki kekuatan dalam penggerakan masyarakat sehingga desiminasi informasi akan terus dilakukan kepada masyarakat di wilayahnya (Sari, Ennimay and Rasyid, 2019). Selain peran kader kesehatan, partisipasi aktif dan kesadaran dari warga dalam kegiatan penyuluhan dan pelatihan upaya kesehatan kerja juga diharapkan agar upaya pengendalian bahaya dan risiko kesehatan dapat terlaksana dengan baik sehingga dapat meminimalkan terjadinya penyakit maupun gangguan kesehatan.

Tahapan kegiatan Upaya Kesehatan Kerja ini dimulai dengan advokasi dan musyawarah dengan ketua RW dan kader kesehatan untuk membangun kesadaran masyarakat pekerja mengenai bahaya dan risiko yang potensial dari aktivitas pekerjaan mereka di sekitar lokasi TPA Cipayung. Tahapan kedua adalah dengan melakukan survey bahaya dan risiko untuk mengidentifikasi bahaya dan menilai risiko yang dihadapi oleh pekerja sebagai akibat dari aktivitas pekerjaannya. Tahap ketiga adalah dengan melakukan penyuluhan mengenai prinsip penerapan K3 dan Ergonomi yang harus dilakukan untuk mengendalikan bahaya dan risiko akibat kerja, serta pelatihan bagi para kader kesehatan tentang pentingnya menerapkan upaya kesehatan kerja. Dari berbagai kegiatan tersebut diharapkan warga dapat melaksanakan berbagai upaya yang dibutuhkan untuk menngendalikan bahaya dan risiko yang potensial di tempat kerja serta melindungi warga yang bekerja dan beraktivitas di sekitar TPA Cipayung dari kemungkinan kecelakaan kerja maupun penyakit akibat kerja.

\section{HASIL DAN PEMBAHASAN}

Hasil observasi dan survei awal menunjukkan bahwa kokasi pemukiman warga sangat dekat dengan TPA Cipayung. Hal tersebut membuat sebagian warga memanfaatkannya sebagai sumber mata pencaharaian sehari-hari. Hal ini dapat terlihat di wilayah RW 7 dan RW 8 dimana 
lokasi TPA Cipayung berada. Banyak warga di area sekitar TPA Cipayung tersebut bekerja sebagai pengangkut dan pengepul sampah dan bersinggungan langsung dengan sampah dan lingkungan yang tercemar sampah.

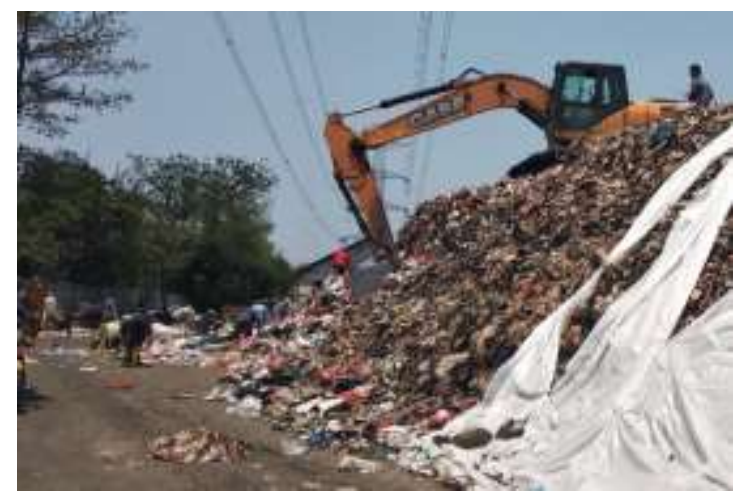

Gambar 1. Warga beraktivitas dan bekerja di area TPA Cipayung

Tingginya tingkat bahaya dan risiko yang harus dihadapi oleh warga yang beraktivitas dan bekerja di sekitar tempat pemrosesan akhir (TPA) harus mendapat perhatian yang mencukupi agar tidak berdampak buruk bagi kesehatan.

Salah satu hal yang dapat dilakukan untuk mengendalikan bahaya dan risiko akibat kerja adalah dengan melaksanakan upaya kesehatan kerja seperti yang diamanatkan dalam Undangundang No. 36 Tahun 2009 pasal 164 yang menyebutkan bahwa upaya kesehatan kerja ditujukan untuk melindungi pekerja agar hidup sehat dan terbebas dari gangguan kesehatan serta pengaruh buruk yang diakibatkan oleh pekerjaan (Pemerintah Indonesia, 2009). Kegiatan yang dilakukan dalam upaya kesehatan kerja TPA Cipayung ini adalah sebagai berikut.

\section{Penyuluhan Penerapan Keselamatan Kerja, Kesehatan Kerja, dan Kesehatan Lingkungan} (K3L)

Upaya Kesehatan Kerja TPA Cipayung adalah bentuk Upaya Kesehatan yang melibatkan masyarakat yang yang bekerja dan beraktivitas di sekitar lokasi TPA Cipayung. Tujuan dari kegiatan Upaya Kesehatan Kerja terutama di sektor informal adalah untuk menjaga keselamatan dan kesehatan pekerja sehingga dapat meminimalkan risiko terjadinya kecelakaan kerja maupun penyakit akibat kerja (Denny et al., 2016).

Penyuluhan Penerapan K3 ini merupakan salah satu kegiatan upaya kesehatan kerja yang dilakukan dengan memberikan materi, wawasan, dan informasi mengenai potensi bahaya apa saja yang ada dalam kegiatan dan pekerjaan yang dilakukan sehari-hari.

Praktik dalam proses Upaya Kesehatan Kerja adalah semua praktik yang dilakukan atas kesadaran sehingga semua anggota yaitu warga pekerja dapat terlibat serta berperan aktif dalam setiap kegiatan yang dilaksanakan (Khair, Sriatmi and Kurniawan, 2018). Dalam kegiatan penyuluhan ini, sebanyak 21 peserta yang terdiri dari kader kesehatan serta para warga Kelurahan Cipayung hadir dan mengikuti jalannya acara secara aktif hingga selesai.

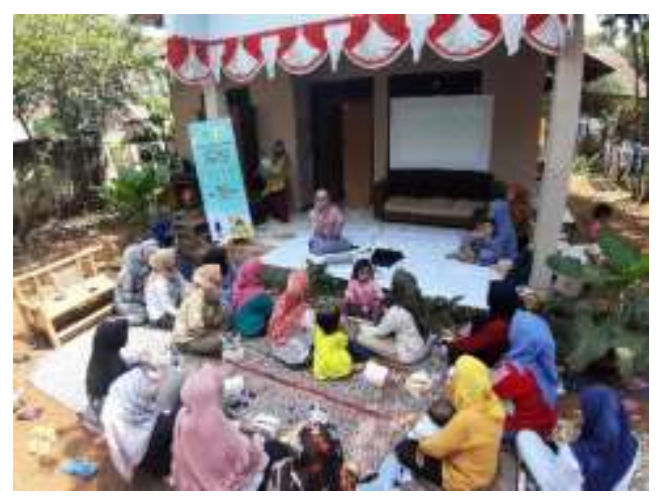

Gambar 2. Kegiatan Penyuluhan Penerapan K3L 
Penyuluhan ini memberikan pemahaman mengenai berbagai bahaya dan risiko yang dihadapi oleh warga dalam aktivitas dan pekerjaan sehari-hari seperti bahaya akibat penggunaan bahan kimia, bahaya penggunaan bahan mudah terbakar dan peralatan tajam, bahaya karena lingkungan yang tidak sehat, serta bahaya yang timbul dari penggunaan peralatan listrik. Kegiatan penyuluhan ini juga membahas bagaimana upaya yang sebaiknya dilakukan untuk menghilangkan atau meminimalkan risiko yang muncul dari bahaya-bahaya tersebut.

\section{Penyuluhan Penerapan Ergonomi}

Penyuluan penerapan ergonomi merupakan kegiatan yang dilakukan sebagai upaya untuk memberikan informasi mengenai bagaimana menerapkan ergonomi dalam kehidupan seharihari. Pengetahuan tentang aplikasi ergonomi dalam kegiatan sehari-hari penting untuk dipahami karena cedera dan penyakit otot rangka jumlahnya sangat tinggi di masyarakat. Bahaya dari faktor ergonomi berasal dari interaksi antara faal kerja manusia dengan pekerjaan dan lingkungan kerjanya. Ergonomi erat kaitannya dengan perancangan sistem kerja yang sesuai dengan aspek dan karakteristik manusia yang memiliki banyak keterbatasan (Kurniawidjaja, 2010).

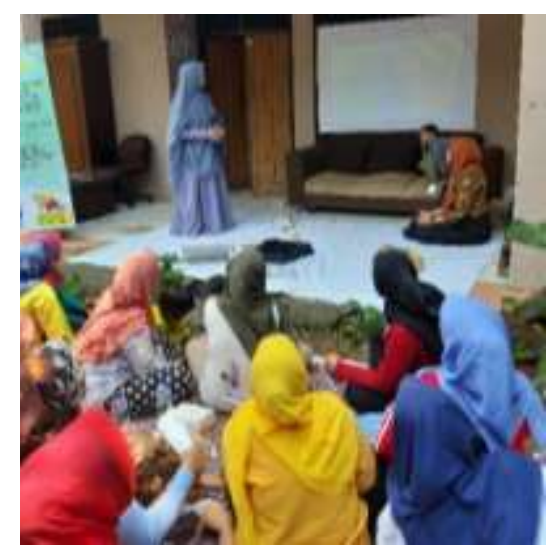

Gambar 3. Kegiatan Penyuluhan Penerapan Ergonomi

Dalam kegiatan penyuluhan penerapan ergonomi ini peserta diberikan informasi mengenai bagaimana melakukan aktivitas sehari-hari dengan ergonomis. Ergonomi harus diaplikasikan dalam kegiatan dan pekerjaan sehari-hari, seperti misalnya saat mengangkat beban, saat menentukan desain peralatan, meja, kursi, dan layout ruangan, serta saat melakukan berbagai aktivitas fisik agar posisi dan postur tubuh selalu ergonomis, sehingga tidak rentan mengalami cidera dan gangguan otot rangka.

\section{Kegiatan Pre-Test dan Post-Test}

Kegiatan Pre-Test dan Post-Test dilakukan sebelum kegiatan penyuluhan dan sesudah kegiatan penyuluhan. Kegiatan Pre-test dan Post-Test ini dilakukan untuk melihat apakah penyuluhan yang telah dilakukan cukup efektif untuk meningkatkan pengetahuan peserta penyuluhan.

Pre-Test dan Post-Test dilaksanakan dengan memberikan soal yang berisi beberapa pertanyaan mengenai pengetahuan dan informasi yang diberikan saat kegiatan penyuluhan. Pertanyaan yang diberikan saat Pre-Test sama dengan pertanyaan yang diberikan saat Post-Test. Seluruh pertanyaan harus dijawab oleh peserta penyuluhan. Kegiatan Pre-Test dan Post-Test ini dilakukan untuk melihat seberapa efektif pemberian pengetahuan dan informasi yang telah dilaksanakan dalam meningkatkan pengetahuan dan pemahaman peserta penyuluhan. Hasil PreTest dan Post-Test peserta penyuluhan kemudian dianalisis untuk mengetahui apakah terdapat perbedaan tingkat pengetahuan pada peserta setelah mengikuti penyuluhan. 
Tabel 1. Analisis Perbedaan Tingkat Pengetahuan Peserta Sebelum dan Setelah Penyuluhan

\begin{tabular}{lrrrrrr}
\hline & Min & Max & Mean & N & SD & P value \\
\hline Pre-test & 30 & 70 & 52 & 20 & 13,6 & \\
$\begin{array}{l}\text { Post- } \\
\text { test }\end{array}$ & 60 & 100 & 86,5 & 20 & 12,26 & \\
\end{tabular}

Keterangan: Min = minimun; $\max =$ maksimum; $n=$ jumlah; $S D=$ standar deviasi; Sumber: Data primer diolah 2019

Tabel 1 menunjukkan data pre-test dan post-test dari 20 peserta yang mengikuti penyuluhan. Dari sebanyak 10 soal yang diberikan, hasil analisis menunjukkan bahwa nilai minimum pre-test adalah 30 dan nilai maksimum 70, dengan nilai rata-rata pre-test adalah 52 . Setelah kegiatan penyuluhan dilakukan terdapat peningkatan nilai, yaitu nilai minimum 60 dan nilai maksimum 100 . Nilai rata-rata post-test adalah 86,5 .

Selanjutnya dilakukan uji wilcoxon untuk mengetahui apakah perbedaan tingkat pengetahuan setelah diberikan penyuluhan cukup signifikan secara statistik. Hasil uji wilcoxon menunjukkan nilai P sebesar 0,001 yang berarti bahwa terdapat perbedaan yang signifikan pada tingkat pengetahuan peserta setelah diberikan penyuluhan. Jika dilihat dari nilai rata-rata yang meningkat sebesar 34,5 poin dapat dikatakan bahwa kegiatan penyuluhan yang telah diadakan mampu meningkatkan pengetahuan peserta mengenai pentingnya penerapan K3L dan ergonomi untuk menjaga dan meningkatkan kesehatan masyarakat.

\section{KESIMPULAN}

Upaya Kesehatan Kerja TPA Cipayung adalah bentuk upaya kesehatan masyarakat yang melibatkan masyarakat yang tinggal, bekerja, dan beraktivitas di sekitar lokasi TPA Cipayung. Upaya kesehatan kerja TPA Cipayung dilaksanakan demi menjaga kesehatan dan kesehatan masyarakat dan pekerja sehingga dapat meminimalkan risiko terjadinya penyakit dan meningkatkan derajat kesehatan masyarakat. Dari kegiatan ini pengetahuan warga dapat ditingkatkan sehingga diharapkan akan dapat mempengaruhi sikap dan perilaku warga serta mendorong peningkatan kualitas kesehatan masyarakat di sekitar TPA Cipayung.

\section{DAFTAR PUSTAKA}

Budiono, A. M. S., Jusuf, R. M. . and Pusparini, A. (2016) Bunga Rampai Hiperkes dan Kesehatan Kerja. Semarang: Badan Penerbit Universitas Diponegoro.

Denny, H. M. et al. (2016) ‘Pembentukan Pos Upaya Kesehatan Kerja pada Industri Kecil Pembuat Alat Rumah Tangga di Kelurahan Bugangan Kota Semarang', Kes Mas: Jurnal Kesehatan Masyarakat, 10(1), pp. 65-68.

Fithri, N. K. (2017) 'Sosialisasi Tentang Penerapan Hidup Bersih dan Sehat di Permukiman Tempat Pembuangan Akhir Sampah ( TPA ) Desa', Jurnal Pengabdian Masyarakat, 4(September).

Khair, M. D. H., Sriatmi, A. and Kurniawan, B. (2018) 'Analisis Perbedaan Proses Pembentukan Pos Upaya Kesehatan Kerja (UKK) Di Kota Semarang', Jurnal Kesehatan Masyarakat, 6(4), pp. 5161.

Kurniawidjaja, L. M. (2010) Teori dan Aplikasi Kesehatan Kerja. Jakarta: Penerbit Universitas Indonesia. 
Pemerintah Indonesia. (2009) Undang-undang No. 36 Tahun 2009 tentang Kesehatan. Indonesia: Sekretarian Negara, Jakarta.

Pemerintah Kota Depok . (2019) Penambahan Sarana dan Prasarana di TPA cipayung Akan Dilakukan Bertahap. Available at: https://www.depok.go.id/03/06/2016/09-lingkungankota-depok/penambahan-sarana-dan-prasarana-di-tpa-cipayung-akan-dilakukan-bertahap (Accessed: 2 January 2019).

Sari, S. M., Ennimay and Rasyid, T. A. (2019) 'Pemanfaatan Tanaman Obat Keluarga (TOGA) pada Masyarakat', Dinamisia: Jurnal Pengabdian Kepada Masyarakat, 3(1), pp. 1-7. doi: https://doi.org/10.31849/dinamisia.v3i2.2833.

Sukrorini, T. et al. (2014) 'Kajian Dampak Timbunan Sampah Terhadap Lingkungan di Tempat Pembuangan Akhir ( TPA ) Putri Cempo Surakarta', Jurnal Ekosains, 6(3), pp. 56-70.

Tibbetts, J. (2013) 'Garbage collection is "one of the most hazardous jobs".', CMAJ: Canadian Medical Association journal = journal de l'Association medicale canadienne, 185(7), p. 4434. doi: 10.1503/cmaj.109-4434. 